Millot, N. 1955. Sensitivity to light and the reactions to changes in light intensity of the echinoid Diadema antillarum Philippi. Philos. Trans. R. Soc. B ser. 238:187-220.

MoORE, J. A. 1957. An embryologist's view of the species concept, p. 325-338. In E. Mayr (ed.), The Species Problem. American Association for the Advancement of Science, Washington.

Mortensen, Th. 1940. A Monograph of the Echinoidea, Vol. III $_{1}$. Aulodonta. C. A. Reitzel, Copenhagen.

MUlleR, H. J. 1942. Isolating mechanisms, evolution and temperature. Biological Symposia 6:71-125.
Paterson, H. E. H. 1978. More evidence against speciation by reinforcement. S. Afr. J. Sci. 74: 369-371.

Pearse, J. S. 1968. Patterns of reproduction in four species of Indo-Pacific echinoderms. Proc. Indian Acad. Sci. (Sect. B) 68:247-279.

- 1975. Lunar reproductive rhythms in sea urchins: a review. J. Interd. Cycle Res. 6:47-52.

SAITo, T. 1976. Geologic significance of coiling direction in the planktonic foraminifera Pulleniatina. Geology 4:305-312.

Templeton, A. R. 1981. Mechanisms of speciation - a population genetic approach. Ann. Rev. Ecol. Syst. 12:23-48.

\title{
POLLEN-OVULE RATIOS AND HERMAPHRODITE SEXUAL ALLOCATION STRATEGIES
}

\author{
DAVID C. QUELLER \\ Division of Biological Sciences, University of Michigan, Ann Arbor Michigan 48109
}

Received November 16, 1982. Revised January 16, 1984

In an intriguing series of papers, the ratio of pollen grain number to ovule number has been shown to be correlated with several aspects of breeding systems in flowering plants. Cruden (1977) shows that the pollen-ovule ratio $(P / O)$ of a species decreases with the degree of self-fertilization and also that outcrossing species with pollen transferred in groups (pollinia or polyads) have unusually low $P / O$ 's (Table 1). In another study of 19 outcrossing species, Cruden and Miller-Ward (1981) found that $P / O$ 's were negatively correlated with both pollen grain surface area $(r=-.864)$ and the ratio of stigmatic area to the pollen-bearing area on the pollinator $(r=-.808)$. While these reports were primarily descriptive, it was suggested that $P / O$ 's may have evolved in the context of "a trade-off between being energetically conservative by minimizing pollen production and providing sufficient excess pollen to assure maximum fecundity" (Cruden, 1977). Charnov $(1979,1982)$ has noted that the selective basis of this argument is questionable and has shown that two of the correlations are consistent with a model of optimal resource allocation between the sexual functions of hermaphrodites. I argue below that the sexual allocation hypothesis provides a useful evolutionary model for understanding all four correlations.

\section{Sexual Resource Allocation Models}

Models of the evolution of sexual allocation in hermaphrodites are formally identical to models of selection on the sex ratio of organisms with separate sexes (Charnov, 1982). In both, there are two equivalent paths of reproduction: for hermaphrodites, male and female gametes; and for gonochorists, male and female offspring. In both cases every new individual receives half of its (autosomal) genes from the male pathway and half from the female pathway, so the total reproduction through the two pathways must be equal. Consequently, selection favors a shift in resource allocation between the sexual functions "if and only if the percentage gain in fitness through one sex function exceeds the percentage loss through the other" (Charnov, 1979, 1982).

The allocation predicted by this "percent rule" depends on the shapes of the male and female gain curves, which describe how relative male fitness and relative female fitness increase with investment in the male and female functions, respectively. When the two curves have the same shape, e.g., linear, the evolutionarily stable allocation is to invest half of the limiting resource in each sexual function. When the curves differ in shape, selection should result in less investment in the sexual function in which returns on investment diminish more, as in sib-mating insects where the value of additional sons diminishes because all daughters can be fertilized by one or two sons (Hamilton, 1967).

\section{Sexual Allocation and P/O's}

Prediction and measurement of sexual allocation may be more difficult in hermaphroditic plants than in gonochoristic animals. First, some investments, such as petals and nectar, are difficult to assign as 
male or female. Second, while there is some information on dry weights or energy contents of male and female parts (Lloyd, 1980; Schoen, 1982), it is rarely known if these measures accurately reflect partitioning of the limiting resource. Third, there is little precise information on the shapes of male and female gain curves.

Lemen (1980) was able to partially circumvent these problems by using the theory to predict differences in allocation among a group of species rather than to predict allocation of a single species. A similar opportunity is afforded by $P / O$ 's. Male investment can be represented by $P \cdot R_{p}$, the number of pollen grains times the investment per grain, and female investment can be similarly represented by $O \cdot R_{o} . R_{p}$ and $R_{o}$ should include all forms of investment in the success of pollen and ovule genes, respectively. For example, $R_{o}$ must include investment in maturing seeds. Under these definitions, $M / F=P R_{p} /\left(O R_{o}\right)$ or, rearranging, $P / O=(M / F)\left(R_{o} /\right.$ $R_{p}$ ). Taking the logarithm of each side (Cruden and Miller-Ward's [1981] data are log-transformed) gives

$$
\log \frac{P}{O}=\log \frac{M}{F}+\log \frac{R_{o}}{R_{p}}
$$

Let $X$ be an ecological or morphological variable which may be correlated with either $M / F$ or $R_{o} / R_{p}$. Designate the least-square regressions of $\log (M / F)$ on $\log (X)$ and $\log \left(R_{o} / R_{p}\right)$ on $\log (X)$ as $\log (M / F)=$ $\alpha+\beta \log (X)$ and $\log \left(R_{o} / R_{p}\right)=\alpha^{\prime}+\beta^{\prime} \log (X)$. From (1) it is then simple to show that the regression of $\log (P / O)$ on $\log (X)$ is

$$
\begin{aligned}
\log \frac{P}{O}= & \left(\alpha+\alpha^{\prime}\right) \\
& +\left(\beta+\beta^{\prime}\right) \log (X) .
\end{aligned}
$$

Bearing in mind that a regression and correlation coefficients have the same sign (since $\beta_{y x}=r_{x y} \cdot \sigma_{y}$ ' $\sigma_{x}$ ), one can predict: 1) if $X$ is predicted to correlate with $M / F$, then it should be correlated in the same direction with $P / O$, provided $X$ is not correlated with $R_{o} / R_{p}\left(\beta^{\prime}=0\right)$; and 2) if $X$ is correlated with $R_{o} / R_{p}$, then it should be correlated in the same direction with $P / O$, provided $X$ is not correlated with $M / F(\beta=0)$.

The first of these approaches attempts to account for whatever fraction of $P / O$ variation is due to variation in $M / F$ 's. The second can account for variation due to different ways of packaging male or female investment within any given $M / F$.

Charnov (1982) used this sort of approach to explain the negative correlation between pollen size and $P / O$. Since pollen size is a major component of $R_{p}$, it should be negatively correlated with $R_{o} /$ $R_{p}$. Therefore, it should also be negatively correlated with $P / O$ 's since there is no reason to believe that pollen size is correlated with $M / F$. It is worth noting in addition that the data are not explained by a simple trade-off between pollen size and number, since the correlation between these measures is not significant (Cruden and Miller-Ward, 1981). A significant correlation arises only when an indi-
TABlE 1. Pollen-ovule ratios and breeding systems (from Cruden, 1977).

\begin{tabular}{lrrr}
\hline \hline & $\begin{array}{c}\text { Num- } \\
\text { ber } \\
\text { spe- } \\
\text { cies }\end{array}$ & \multicolumn{1}{c}{$\begin{array}{c}\text { Mean } \\
\text { Breeding system }\end{array}$} & $\begin{array}{r}\text { Mean } \\
\text { of SE }\end{array}$ \\
\hline Cleistogamy & 6 & 4.7 & .7 \\
Obligate autogamy & 7 & 27.7 & 3.1 \\
Facultative autogamy & 20 & 168.5 & 22.1 \\
Facultative xenogamy & 38 & 796.6 & 87.7 \\
Xenogamy & 25 & $5,859.2$ & 936.5 \\
\cline { 2 - 5 } Xenogamy with clumped & & & \\
$\quad$ pollen transfer & 12 & 236.9 & 16.9 \\
\hline
\end{tabular}

cator of relative female investment, here ovule number, is included.

Charnov (1979) also suggested that the decrease in $P / O$ 's with self-fertilization is analogous to the decrease in sons due to local mate competition in sib-mating insects, and Charlesworth and Charlesworth (1981) confirmed through genetic modelling that selfing should select for a smaller fraction of resources being devoted to pollen production. However, this model is slightly different from the basic allocation model discussed here. It searches for the best allocation of resources between (outcrossing) pollen and seeds. It cannot, and does not, start from an observation that the total reproduction through these two routes is equal. Instead, the fractions of the total reproduction through these routes are treated as variables that depend on the selfing rate; the more a species selfs, the higher the fraction of the average individual's reproduction is transmitted through seeds rather than outcrossing pollen.

While this approach is quite correct, it is worth pointing out that decreased pollen investment with selfing can also be understood in terms of an allocation model founded on the usual starting point of two equivalent reproductive pathways. The total number of nuclear genes transmitted through pollen (which I will call "male genes") equals the total transmitted through ovules ("female genes"). The "percent rule" is therefore valid for division of a limiting resource between investments that further the success of male and female genes. In this model, investment in a self-fertilized seed must be viewed as half male and half female, because it furthers the investing individual's reproduction through male and female genes equally. I do not mean to enshrine this as the only biologically valid definition of male and female investment; it is simply the definition appropriate for an allocation model for which the percent rule is valid.

Under this definition, $R_{p}$ and $R_{o}$ differ between selfing and outcrossing species. $R_{p}$ is relatively larger in a selfer because it includes not only investment in the pollen grain itself, but also half the investment in self-fertilized seeds. By the same token, $R_{o}$ is relatively smaller in selfing species. As a consequence, the selfing habit should be negatively correlated with $R_{o} / R_{p}$ and, from (2), similarly corre- 
lated with $P / O$ 's. Even if there were no local mate competition among pollen grains, selfers would still have lower $P / O$ 's. There may be an additional effect due to local mate competition, but it is not required to generate the correlation.

I stress that this approach and the one taken by Charlesworth and Charlesworth (1981) are alternative but equivalent ways of dissecting the same evolutionary process. The former has the advantage of being formally identical to other sex allocation models while the latter has the advantage of solving directly for investment in the units of interest, pollen and seeds.

The association between transfer of clumped groups of pollen and low $P / O$ 's is explicable by a combination of local mate competition and a possible difference in $R_{o} / R_{p}$ ratios. Consider the options available to a milkweed species in which the pollen grains within each anther sac adhere and are transferred as a unit, called a pollinium, to a stigmatic surface, where they compete with each other for the available ovules. This local mate competition (but not for siblings) should select for fewer grains per anther sac than is usual in non-pollinial species, unless having many grains is crucial for competition against other pollinia. Such betweenpollinium competition for ovules is probably uncommon in Asclepias exaltata and $A$. viridiflora, in which $59 \%$ ( 91 of 155$)$ and $82 \%$ (267 of 325$)$ of the pollinia found inserted at stigmatic surfaces had no competing pollinia inserted on the same flower (author's unpubl. data). Since flowers are receptive for 7-9 days, temporal spacing will reduce betweenpollinium competition even on multiply-pollinated flowers.

Local mate competition should therefore select for lower $P / O$ 's and $M / F$ 's in pollinial species although $M / F$ 's could be maintained by some compensatory form of male investment, a possibility permitted, but not required, by sex allocation theory. While there are other ways to invest in male success (Willson, 1979), these would not cause $P / O$ 's to be maintained at their former levels. A pollinial plant might compensate for fewer pollen grains per anther sac by producing more pollinia per flower or more flowers, but the success of these measures would require (a) more pollinator activity if the additional pollinia are to be of any use and (b) some mechanism, such as fruit abortion, to prevent the increased pollinator activity from also increasing female investment. The extra investment in attractants and rewards for pollinators must be viewed as male investment. Thus, any compensation by pollinial species would come about, at least in part, through increasing $R_{p}$ or by decreasing (through abortion) $R_{o}$. Therefore, even if $M / F$ 's remained unchanged because of compensation, $P / O$ 's would still be lower than usual because of the lower values of $R_{o} / R_{p}$ (see equation 2). This argument would also apply, though perhaps with less force, to species in which pollen clumping is less pronounced, such as the clumping due to viscin threads in the Onagraceae (see Cruden and Jensen, 1979).
Several studies have shown that large flower numbers in milkweeds are more important in enhancing pollinium removal and presumed success than in increasing fruiting (Willson and Rathcke, 1974; Willson and Price, 1977; Chaplin and Walker, 1982; Queller, 1983). This lends credence to an evolutionary scenario that begins with the evolution of pollinia and is followed by reduction of pollen grains per pollinium due to local mate competition, compensation by production of additional flowers, and abortion of the resulting "excess" fruits. A possible alternative, also consistent with sex allocation theory, is that the evolution of pollinia permitted plants to produce larger numbers of ovules and seeds per fruit if there were any advantage in doing so. $M / F$ 's would then remain at optimal levels only if fewer fruits were matured. Both of these forces may have been involved and both suggest that fruit abortion in milkweeds could be an adaptation that allows resources to be put to more efficient use in promoting male success.

A similar argument applies to the negative correlation between $P / O$ 's and the ratio of the stigmatic area to the pollen-bearing area on the pollinator. Large stigmas and small pollen-bearing areas should both tend to increase competition among pollen grains from the same plant relative to competition among pollen grains from different plants. First, small pollen-bearing areas may limit the amount of pollen that can be picked up when a pollinator visits a plant. Second, pollen picked up on a small pollen-bearing area will more often be deposited en masse on the first stigma contacted, particularly if the stigma is large. The result is an approach to the grouped transfer of pollen characteristic of pollinial species and the expected result is the same: selection for fewer pollen grains, perhaps followed by compensatory male investments not reflected in pollen number. $P / O$ 's should therefore be relatively low. Since the grouping of pollen is not so pronounced, the effect should be less than in pollinial species, but it would be interesting to see if seed abortion is also common in these species.

In conclusion, the theory of sex allocation provides a framework for understanding the evolution of $P / O$ 's. This is not to say that all variation in $P / O$ 's is due to selection on sex allocation. Some of it results instead from differences in the way given amounts of male or female investment can be packaged, and a full treatment of selection on $P / O$ 's will need to consider the merits of the various packaging alternatives. Imperfect as they are as estimators of relative investment ratios, $P / O$ 's comprise the most extensive data set available for testing the theory of sex allocation in hermaphrodites, and they show at least a qualitative fit with the theory. As better data become available, more precise tests, and tests of other predictions (Lloyd, 1980; Charlesworth and Charlesworth, 1981; Charnov, 1982), will become possible.

\section{SumMary}

Pollen-ovule ratios of flowering plants have pre- 
viously been shown to be negatively correlated with self-fertilization, clumped pollen transfer, pollen size, and the ratio of stigma area to the pollen-bearing area on the pollinator. Here, the four correlations are shown to be consistent with evolutionary models of optimal allocation of resources to male and female functions, providing evidence that selection on sex allocation in hermaphrodites is governed by the same principles as selection on the sex ratio.

\section{ACKNOWLEDGMENTS}

Part of this work was conducted under an N.S.F. predoctoral fellowship. For helpful comments on drafts of the manuscript, I thank W. D. Hamilton, R. D. Alexander, B. J. Rathcke, W. H. Wagner, D. Rabinowitz, anonymous referees, and especially $R$. W. Cruden.

\section{Literature Crted}

Chaplin, S. J., AND J. L. Walker. 1982. Floral display of a forest milkweed: energetic constraints and the adaptive value of the floral arrangement. Ecology 63:1857-1870.

Charlesworth, D., and B. Charlesworth. 1981. Allocation of resources to male and female functions of hermaphrodites. Biol. J. Linn. Soc. 15: 57-74.

Charnov, E. L. 1979. Simultaneous hermaphroditism and sexual selection. Proc. Nat. Acad. Sci. USA 76:2480-2484.

- 1982. The theory of sex allocation. Princeton Univ. Press, Princeton.
Cruden, R. W. 1977. Pollen-ovule ratios: a conservative indicator of breeding systems in flowering plants. Evolution 31:32-46.

Cruden, R. W., AND K. G. Jensen. 1979. Viscin threads, pollination efficiency and low pollenovule ratios. Amer. J. Bot. 66:875-879.

Cruden, R. W., ANd S. Miller-Ward. 1981. Pollen-ovule ratio, pollen size and the ratio of stigmatic area to the pollen bearing area of the pollinator: an hypothesis. Evolution 35:964-974.

Hamilton, W. D. 1967. Extraordinary sex ratios. Science 156:477-488.

LEMEN, C. 1980. Allocation of reproductive effort to the male and female strategies in wind-pollinated plants. Oecologia 45:156-159.

LLOYD, D. G. 1980. Parental strategies of angiosperms. New Zealand J. Bot. 17:595-606.

Queller, D. C. 1983. Sexual selection in a hermaphroditic plant. Nature 305:706-707.

SCHOEN, D. J. 1982. Male reproductive effort and breeding system in an hermaphroditic plant. Oecologia 53:255-257.

WILLSON, M. F. 1979. Sexual selection in plants. Amer. Natur. 113:777-790.

Willson, M. F., and P. W. Price. 1977. The evolution of inflorescence size in Asclepias (Asclepiadaceae). Evolution 31:495-511.

Willson, M. F., AND B. J. RathCKe. 1974. Adaptive design of the floral display in Asclepias syriaca L. Amer. Midl. Natur. 92:47-57.

Corresponding Editor: Stephen G. Weller

\title{
POPULATION DENSITY, OUTCROSSING RATE, AND HETEROZYGOTE SUPERIORITY IN PONDEROSA PINE
}

\author{
Michael A. Farris and JefFry B. Mitton \\ Department of Environmental, Population, and Organismic Biology, University of Colorado, \\ Boulder, Colorado 80309
}

Received November 14, 1983. Revised March 28, 1984

The analysis of protein polymorphisms via electrophoresis has proven to be a useful tool in the study of several facets of population genetics. In this paper, we examine two of these facets-variation in the mating system and the phenomenon of heterozygote advantage-in ponderosa pine (Pinus ponderosa Laws). The mating system of a plant species may show variation which is due to either genetic or environmental factors. One of the environmental factors which may be important in determining outcrossing rates is plant density. In animal-pollinated species, higher plant densities generally lead to shorter pollinator flights (Wolf, 1969; Ehrlich and Gilbert, 1973; Levin and Kerster,
1974). Shorter flight distances should restrict gene flow, allowing greater differentiation among and within populations and higher levels of inbreeding. These expectations are consistent with the results of computer simulations (Turner et al., 1982) and field studies (Ellstrand et al., 1978).

Plant density should have the opposite effect on the mating system of wind-pollinated species, as pollen dispersal in anemophilous plants decreases exponentially with distance (summarized in Levin and Kerster, 1974). An individual in a high density population will be in contact with a pollen cloud containing a relatively small portion of its own pollen; therefore, most seeds will be a product of out- 